\title{
Adsorption of Chromium(VI) from Aqueous Solutions by Coffee Polyphenol-Formaldehyde/Acetaldehyde Resins
}

\author{
Khudbudin Mulani, Siona Daniels, Kishor Rajdeo, Sanjeev Tambe, and Nayaku Chavan \\ Polymer Science and Engineering Division, National Chemical Laboratory, Dr. Homi Bhabha Road, Pune 411008, India \\ Correspondence should be addressed to Nayaku Chavan; nn.chavan@ncl.res.in
}

Received 26 August 2013; Accepted 22 November 2013

Academic Editor: Ridvan Say

Copyright ( 2013 Khudbudin Mulani et al. This is an open access article distributed under the Creative Commons Attribution License, which permits unrestricted use, distribution, and reproduction in any medium, provided the original work is properly cited.

\begin{abstract}
Removal of chromium(VI) from wastewater is essential as it is toxic. Thus, removal of chromium(VI) was performed using coffee polyphenol-formaldehyde/acetaldehyde resins as adsorbents. Adsorbent resins were prepared by condensation of decaffeinated coffee powder with formaldehyde/acetaldehyde and used for the removal of $\mathrm{Cr}(\mathrm{VI})$ ions from aqueous solutions. A simple and sensitive solid phase extraction procedure was applied for the determination of chromium at trace levels by spectroscopic method using 1,5-diphenylcarbazide reagent. The adsorption of $\mathrm{Cr}(\mathrm{VI})$ on the coffee polyphenol-formaldehyde/acetaldehyde resins was monitored by FTIR and EDX analysis. The metal adsorption parameters such as contact time, $\mathrm{pH}, \mathrm{Cr}(\mathrm{VI})$ ion concentration, and adsorbent dose were investigated. For $\mathrm{Cr}(\mathrm{VI})$, the maximum adsorption capacity of coffee polyphenol-formaldehyde resins was $98 \%$ at $\mathrm{pH}$ 2. The experimental results showed that $\mathrm{Cr}(\mathrm{VI})$ bound strongly with coffee polyphenol-formaldehyde/acetaldehyde resins and utilization of resins could be improved greatly by reuse.
\end{abstract}

\section{Introduction}

Metal ions such as $\mathrm{Cd}, \mathrm{Cr}, \mathrm{Co}, \mathrm{Cu}, \mathrm{Zn}, \mathrm{Pd}, \mathrm{Hg}, \mathrm{Ni}, \mathrm{Ag}$, and $\mathrm{Sr}$ and metalloids such as $\mathrm{Se}, \mathrm{As}$, and $\mathrm{Sb}$ are toxic beyond trace levels. Most of these trace elements are transition metals with variable oxidation states and coordination numbers. Strong exposure to $\mathrm{Cr}(\mathrm{VI})$ causes cancer in the digestive tract and lungs. It may also cause gastric pain, nausea, vomiting, severe diarrhea, and hemorrhage $[1,2]$.

Treatment of wastewater generated by industrial processes today is of prime concern. Various technologies have been developed over recent years and are available for the removal of toxic metal such as chromium from wastewater [3]. Chromium bearing wastewater originates from a variety of industrial processes such as electroplating, dichromate and basic chrome sulphate manufacturing, tannery, anodizing, cutting tools, and chrome mining. Many of these industrial processes usually produce a large volume of wastewater with a chromium concentration ranging from less than $1 \mathrm{ppm}$ to $10 \mathrm{ppm}$.

The two common oxidation states of chromium observed in natural water are $\mathrm{Cr}(\mathrm{III})$ and $\mathrm{Cr}(\mathrm{VI})$. $\mathrm{Cr}(\mathrm{III})$ is not a significant groundwater contaminant, whereas $\mathrm{Cr}(\mathrm{VI})$ is approximately 100 times more toxic than $\mathrm{Cr}$ (III) [4].

Conventional methods used for removing $\mathrm{Cr}(\mathrm{VI})$ ions from industrial wastewater include reduction followed by chemical precipitation, adsorption on activated carbon, solvent extraction, freeze separation, reverse osmosis, ion exchange, and electrolytic methods. These methods have found limited applications because they often involve high capital and operational costs. Adsorption is an effective and versatile method for removing chromium which solves the problem of sludge disposal and renders the system more economically viable, especially if low-cost adsorbents are used [5-9]. The major advantage of adsorption is its high selectivity and enrichment factor.

A wide range of commercial sorbents including chelating reagents and activated carbon are available for adsorption, but they are relatively expensive. In recent years, low-cost natural materials have been proposed as potential biosorbents. These include moss peat, algae, leaf mould, sea weeds, coconut husk, sago waste, peanut hull, hazelnut, bagasse, rice hull, sugar beet pulp, plant biomass, bituminous coal, and coffee powder [10-21]. 
High proportions of aromatic compounds present in coffee beans are phenolics, presumably derived from chlorogenic acid and melanoidins [20,21]. Coffee melanoidins are formed on roasting coffee beans and they have the ability to chelate metal ions.

In the present study, adsorbent resins were prepared from condensation of coffee polyphenol and formaldehyde/acetaldehyde for $\mathrm{Cr}(\mathrm{VI})$ removal. The effect of various parameters on adsorption of $\mathrm{Cr}(\mathrm{VI})$ such as $\mathrm{pH}$, contact time, $\mathrm{Cr}(\mathrm{VI})$ concentration, adsorbent dose, and desorption were investigated.

\section{Materials and Methods}

2.1. Materials. Roasted coffee beans were procured from a local source, crushed in a grinder, and sieved through $355 \mu \mathrm{m}$ pore size filter. Sieved coffee powder was treated with chloroform to remove caffeine. The activated decaffeinated coffee polyphenol powder was further treated with formaldehyde/acetaldehyde solution in the presence of ammonia. Kinetic studies using batch experimental method were carried out for the removal of $\mathrm{Cr}(\mathrm{VI})$ from aqueous solutions. Acetaldehyde (35\%), ammonia solution (25\%), sulfuric acid (98\%), and nitric acid (70\%) were purchased from Merck, India. Formaldehyde (37\% solution) was obtained from Qualigen, India. Stock solution of Cr(VI) $(17.6 \mathrm{mg} / \mathrm{mL})$ was prepared by dissolving accurately weighed potassium dichromate $\left(\mathrm{K}_{2} \mathrm{Cr}_{2} \mathrm{O}_{7}\right.$, Loba Chemie Pvt. Ltd. Mumbai, India) in $100 \mathrm{~mL}$ deionized water. A solution (0.025\%) of 1,5diphenylcarbazide (DPC, Sigma-Aldrich, USA) was prepared by dissolving $25 \mathrm{mg}$ of DPC in $5 \mathrm{~mL}$ of acetone (Merck) and $10 \mathrm{~mL}$ of $5 \mathrm{M} \mathrm{H}_{2} \mathrm{SO}_{4}$. This mixture was diluted to $100 \mathrm{~mL}$ with deionised water and stored in an amber-glass bottle. Water was deionised and purified with a Milli-Q water purification system (Millipore, USA). Freshly prepared solutions were used for all experiments. All chemicals were used without purification.

\subsection{Preparation of Coffee Polyphenol-Formaldehyde (CFA)} Resin. The composition of reactants is illustrated in Table 1. In a $100 \mathrm{~mL}$ plastic container, $4 \mathrm{~g}$ of activated decaffeinated coffee powder and desired amount (5 to $25 \mathrm{~mL}$ ) of $37 \%$ formaldehyde solution were added and stirred for $5 \mathrm{~min}$ to achieve uniform mixing. To this mixture, $10 \mathrm{~mL}$ ammonia (25\%) solution was added and stirred for an additional $5 \mathrm{~min}$. The resulting reaction mixture was kept for 15 days at room temperature. A precipitate was observed at the bottom of the plastic container. The reaction mixture was neutralized with $1 \mathrm{M}$ hydrochloric acid solution and the precipitate formed was filtered using a filter paper. The precipitate was treated with 1.2 $\mathrm{M}$ hydrochloric acid solution to make it insoluble in both acidic and basic medium. The solution was filtered and the residue was treated with deionized water followed by drying at $80^{\circ} \mathrm{C}$ for $8 \mathrm{~h}$ so as to obtain insoluble coffee polyphenolformaldehyde resins. Analysis of particle size was in the range of 20.85 to $28.29 \mu \mathrm{m}$. These resins were prepared in duplicate to check reproducibility and whether results obtained were within the same range.
TABLE 1: Composition of coffee polyphenol-formaldehyde (CFA) resins.

\begin{tabular}{lccc}
\hline Resin code & $\begin{array}{c}\text { Coffee powder } \\
(\mathrm{g})\end{array}$ & $\begin{array}{c}\text { Formaldehyde } \\
(\mathrm{mL})\end{array}$ & $\begin{array}{c}\text { Ammonia } \\
(\mathrm{mL})\end{array}$ \\
\hline CFA 01 & 4 & 5 & 10 \\
CFA 02 & 4 & 10 & 10 \\
CFA 03 & 4 & 15 & 10 \\
CFA 04 & 4 & 20 & 10 \\
CFA 05 & 4 & 25 & 10 \\
\hline
\end{tabular}

TABLE 2: Composition of coffee polyphenol-acetaldehyde (CAA) resins.

\begin{tabular}{lccc}
\hline Resin code & $\begin{array}{c}\text { Coffee powder } \\
(\mathrm{g})\end{array}$ & $\begin{array}{c}\text { Acetaldehyde } \\
(\mathrm{mL})\end{array}$ & $\begin{array}{c}\text { Ammonia } \\
(\mathrm{mL})\end{array}$ \\
\hline CAA 01 & 4 & 5 & 10 \\
CAA 02 & 4 & 10 & 10 \\
CAA 03 & 4 & 15 & 10 \\
CAA 04 & 4 & 20 & 10 \\
CAA 05 & 4 & 25 & 10 \\
\hline
\end{tabular}

2.3. Preparation of Coffee Polyphenol-Acetaldehyde (CAA) Resin. The composition of reactants is presented in Table 2. In a $100 \mathrm{~mL}$ plastic container, $4 \mathrm{~g}$ of activated decaffeinated coffee powder and desired amount ( 5 to $25 \mathrm{~mL}$ ) of acetaldehyde solution (35\%) were added and stirred for $5 \mathrm{~min}$ to achieve uniform mixing. To this mixture, $10 \mathrm{~mL}$ ammonia (25\%) solution was added and stirred for an additional $5 \mathrm{~min}$. The resulting reaction mixture was kept for 15 days at room temperature. A precipitate was observed at the bottom of the plastic container. The reaction mixture was neutralized with $1 \mathrm{M}$ hydrochloric acid solution and the precipitate formed was filtered using ordinary filter paper. Precipitate obtained was treated with 1.2 M hydrochloric acid to make it insoluble in both acidic and basic medium. The solution was filtered and the residue was treated with deionized water followed by drying at $80^{\circ} \mathrm{C}$ for $8 \mathrm{~h}$ so as to obtain insoluble coffee polyphenol-acetaldehyde resins. Analysis of particle size was in the range of 16.71 to $26.23 \mu \mathrm{m}$. These resins were prepared in duplicate to check reproducibility and whether results obtained were within the same range.

2.4. Resin Characterization. IR spectra of resins were recorded on FTIR (PerkinElmer) spectrophotometer. The samples were prepared after drying the resins at $80^{\circ} \mathrm{C}$ for $4 \mathrm{~h}$. Potassium bromide (spectrometry grade) was dried at $150^{\circ} \mathrm{C}$ for $4 \mathrm{~h}$ and pellets were prepared by mixing $1 \mathrm{mg}$ of sample with $100 \mathrm{mg}$ of potassium bromide. IR spectra were recorded from 4000 to $450 \mathrm{~cm}^{-1}$ (8 scans) on potassium bromide pellets. Scanning electron microscope (SEM) and EDX measurements were conducted using BRUKER AXS, $\mathrm{X}$-flash detector 5010 at an acceleration voltage of $0-20 \mathrm{keV}$. Particle size distribution was determined using Accusizer 780 Optical Particle Sizer (PSS-Nicomp, Particle Sizing System, Santa Barbara, CA, USA). 


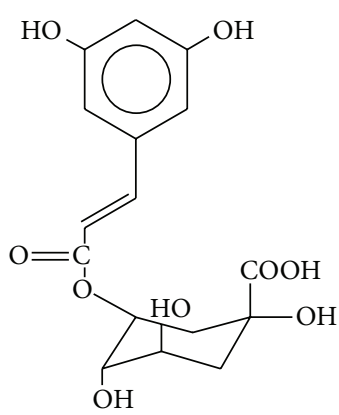

Chlorogenic acid

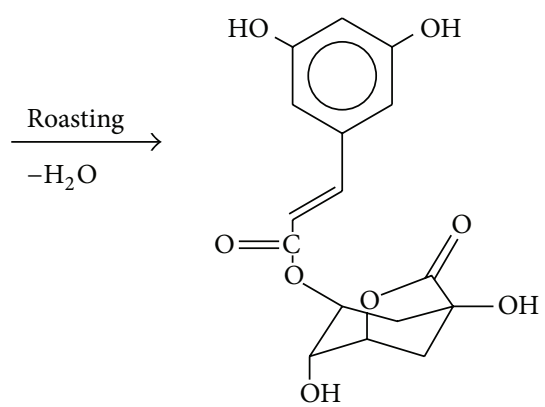

Coffee melanoidins

FIGURE 1: Chlorogenic acid and its roasted form.

2.5. Adsorption of $\mathrm{Cr}(\mathrm{VI})$. Batch method was used to investigate the adsorption study of $\mathrm{Cr}(\mathrm{VI})$ onto $\mathrm{CFA}$ and $\mathrm{CAA}$ resins. To study the effect of $\mathrm{pH}$ on $\mathrm{Cr}(\mathrm{VI})$ sorption, $100 \mathrm{mg}$ of resin was immersed into $10 \mathrm{~mL}(17.6 \mathrm{ppm}) \mathrm{Cr}(\mathrm{VI})$ stock solution at different $\mathrm{pH}$. The mixture was stirred at room temperature for $24 \mathrm{~h}$. The concentration of $\mathrm{Cr}(\mathrm{VI})$ ions in the effluent was determined spectrophotometrically by the development of a pink color with a complexing agent 1,5diphenyl carbazide in acidic solution. Absorbance of the pink-colored solution was measured at $\lambda 540 \mathrm{~nm}$ after $20 \mathrm{~min}$ against blank. Based on the optimum conditions, Beer's law holds well within the concentration range $0.08-0.51 \mathrm{mg} / \mathrm{mL}$ and the regression equation is $Y=4.332 X$ with a correlation coefficient of 0.9968 .

\section{Results and Discussion}

3.1. Coffee Polyphenol-Formaldehyde/Acetaldehyde Resin. Aromatic compounds found in coffee beans are mainly phenolic compounds. Robusta coffee has slight higher phenolic content than Arabica [20,21]. Decaffeinated coffee beans were crushed in a grinder and sieved through $355 \mu \mathrm{m}$ pore size filter. Sieved coffee powder was further treated with chloroform to remove alkaloids such as caffeine and trigonelline. The residue contains mostly chlorogenic acid and coffee melanoidins, useful from the resin's point of view $[22,23]$. The structure of coffee melanoidins is presented in Figure 1. Adsorbents were prepared by condensation of decaffeinated coffee powder with formaldehyde/acetaldehyde in the presence of ammonia. Batch experiments were carried out to study the kinetics of removal of $\mathrm{Cr}(\mathrm{VI})$ from aqueous solutions.

Comparison plot of adsorption of chromium with blank coffee power, coffee-polyphenol-formaldehyde, and coffeepolyphenol-acetaldehyde resins is shown in Figure 2 and it showed that the adsorption of blank coffee powder was lower than coffee-formaldehyde resins. Our objective was to develop new resins with coffee powder for toxic metal removal which should have better thermal and mechanical performance. So that, the same resins can be used repeatedly thus increasing turn over number which would be economically beneficial. Blank coffee powder does not have enough thermal or mechanical performance, because basically it contains organic compounds, which will not serve our purpose.

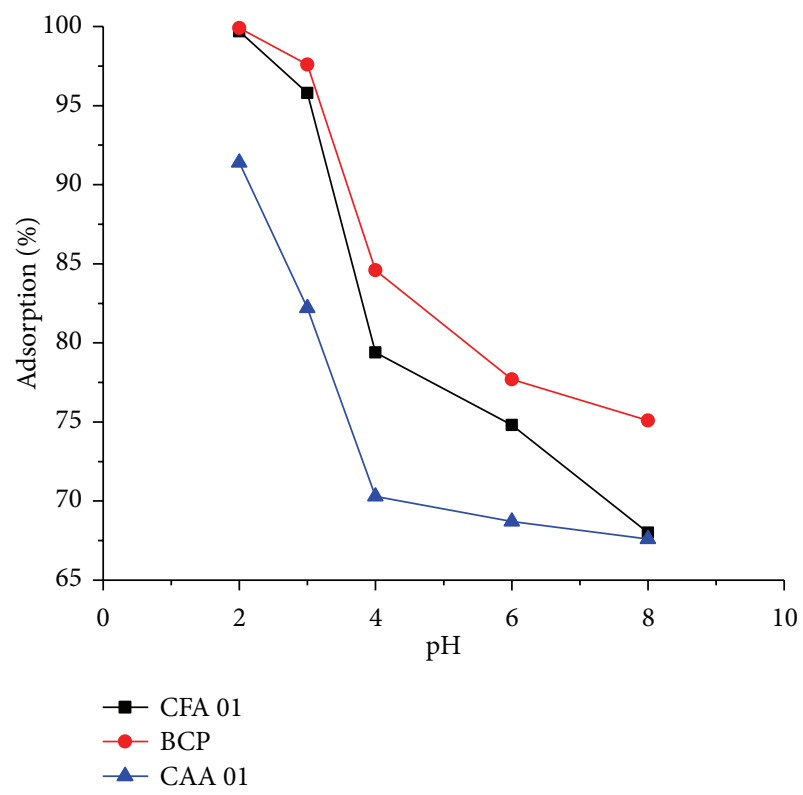

FIGURE 2: Comparison of coffee polyphenol based resins on chromium adsorption. CFA: coffee polyphenol-formaldehyde resins; CAA: coffee polyphenol-acetaldehyde resins; BCP: blank coffee powder.

In this case, formaldehyde acts as a cross-linker and forms coffee polyphenol-formaldehyde/acetaldehyde resins. Coffee contains polyphenols which are linked together by forming $-\mathrm{CH}_{2}-$ bridges. The resins prepared by condensation polymerization of coffee polyphenols with formaldehyde/acetaldehyde are thus insoluble in acidic as well as basic media and increasing reusability and simultaneously turn over number.

Mainly two cross-linkers such as formaldehyde and acetaldehyde were studied to see the effect on chromium metal adsorption. It was observed that formaldehyde $\left(\mathrm{pK}_{\mathrm{a}}\right.$, 13.3) showed higher chromium adsorption than acetaldehyde (13.57) due to more acidic nature and steric hindrance.

3.2. Fourier Transform Infrared Analysis. FTIR spectroscopy was used to identify the functional groups present in roasted coffee bean powder. Roasted coffee bean powder has a 


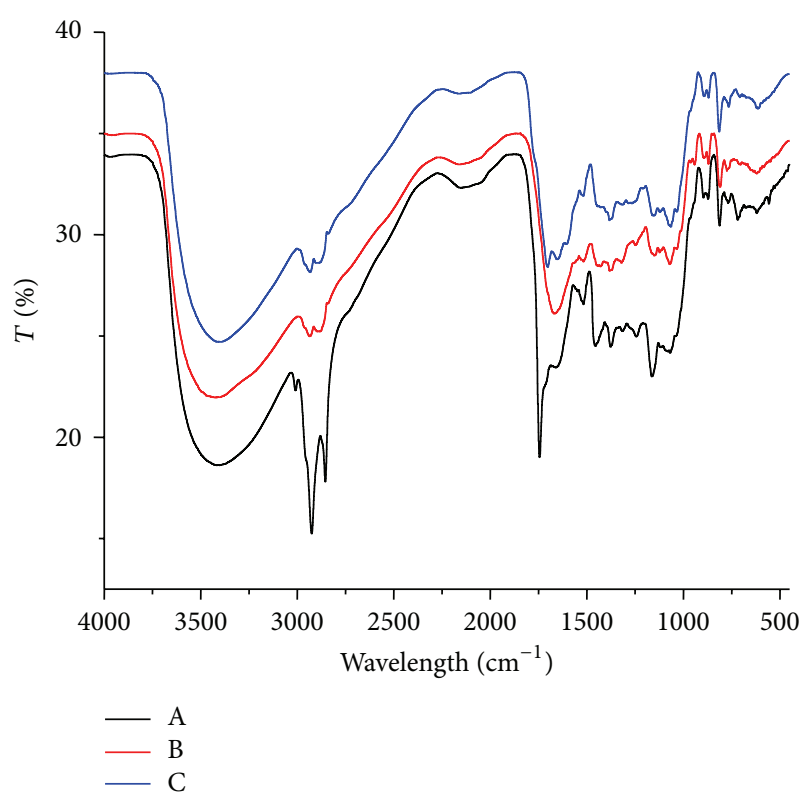

FIGURE 3: FTIR spectra of decaffeinated coffee powder (A), coffee polyphenol-formaldehyde resins (virgin) (B), and coffee polyphenol-formaldehyde resins with $\mathrm{Cr}(\mathrm{VI})(\mathrm{C})$.

variety of functional groups such as hydroxyl, carboxyl, carbonyl, amino and imino, which are important sites for metal sorption. The FTIR spectra of blank decaffeinated coffee powder (A), coffee polyphenol-formaldehyde resins (B), and $\mathrm{Cr}(\mathrm{VI})$ adsorbed coffee polyphenol-formaldehyde resins powder (C), respectively, are depicted in Figure 3. The absorbance bands observed at 3423 and 2934 are assigned to $-\mathrm{OH}$ and $-\mathrm{CH}_{2}$ stretching, respectively. The sharp peak observed at $1744 \mathrm{~cm}^{-1}$ for decaffeinated coffee is due to the $\mathrm{C}=\mathrm{O}$ stretching of carboxyl acid, ketone, or its ester. The small peak observed at $1080 \mathrm{~cm}^{-1}$ is due to the $\mathrm{N}=\mathrm{C}$ stretching of caffeine. All the absorptions observed at 3423, 2934, 2884, 1744 , and $1665 \mathrm{~cm}^{-1}$ are shifted to higher wavelength with adsorption of $\mathrm{Cr}(\mathrm{VI})$ ion. From these results, it is presumed that the $\mathrm{Cr}(\mathrm{VI})$ metal ion is incorporated with CFA resins through interaction with active functional groups such as $-\mathrm{OH}$ and $-\mathrm{CO}-$.

3.3. Effect of $p H$. The $\mathrm{pH}$ of aqueous solution is a significant parameter for the removal of metal ions by adsorption [24]. Adsorption of $\mathrm{Cr}(\mathrm{VI})$ was studied in the $\mathrm{pH}$ range of 1-8 and the effect of $\mathrm{pH}$ on $\mathrm{Cr}(\mathrm{VI})$ removal using coffee-polyphenolformaldehyde and coffee-polyphenol-acetaldehyde resins is shown in Figures 4 and 5, respectively.

The experimental results reveal that $\mathrm{Cr}(\mathrm{VI})$ removal efficiency increases with the decrease in $\mathrm{pH}$ and reached up to $99.7 \%$ at $\mathrm{pH} 2$. $\mathrm{Cr}(\mathrm{VI})$ exists in aqueous phase in different anionic forms such as chromate $\left(\mathrm{CrO}_{4}{ }^{2-}\right)$, dichromate $\left(\mathrm{Cr}_{2} \mathrm{O}_{7}{ }^{2-}\right)$, or hydrogen chromate $\left(\mathrm{HCrO}_{4}{ }^{-}\right)$as depicted in Figure 6. The dominant form of $\mathrm{Cr}(\mathrm{VI})$ at lower $\mathrm{pH}$ is $\mathrm{HCrO}_{4}{ }^{-}$[25]. Shifts of $\mathrm{HCrO}_{4}{ }^{-}$to other forms $\mathrm{CrO}_{4}{ }^{2-}$ and $\mathrm{Cr}_{2} \mathrm{O}_{7}{ }^{2-}$ increase with the $\mathrm{pH}$. From these results, it

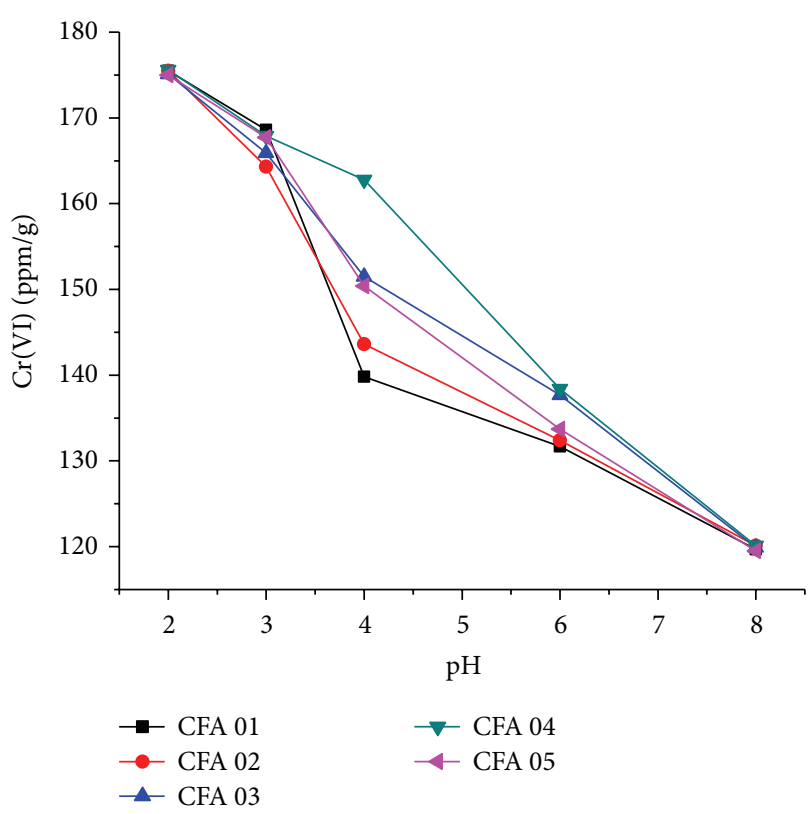

FIgURE 4: Effect of $\mathrm{pH}$ on $\mathrm{Cr}(\mathrm{VI})$ adsorption by CFA resins.

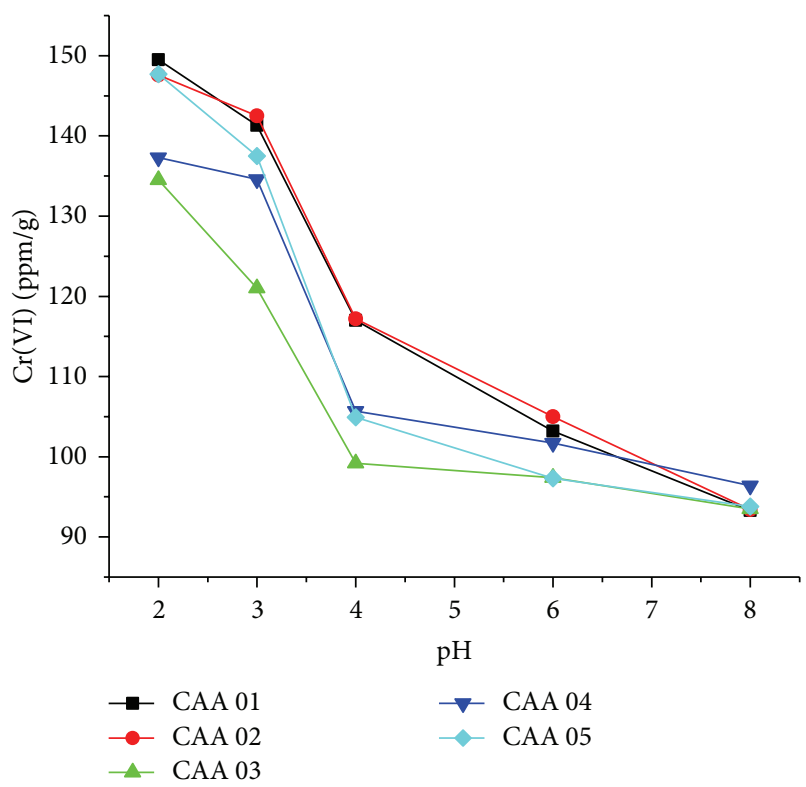

Figure 5: Effect of $\mathrm{pH}$ on $\mathrm{Cr}(\mathrm{VI})$ adsorption by CAA resins.

can be concluded that the active form of $\mathrm{Cr}(\mathrm{VI})$ can be adsorbed onto $\mathrm{HCrO}_{4}{ }^{-}$. The adsorption of $\mathrm{Cr}(\mathrm{VI})$ is more effective on coffee polyphenol-formaldehyde/acetaldehyde adsorbents. Some of the functional groups such as phenolic $-\mathrm{OH}$ bind electrostatically with negatively charged metal complexes. The decrease in the adsorption with increase in $\mathrm{pH}$ may be due to the decrease in electrostatic force of attraction between sorbent and sorbate ions. At lower $\mathrm{pH}$, the percentage of $\mathrm{Cr}(\mathrm{VI})$ removal is high as the surface of adsorption becomes protonated; thus, the electrostatic force of attraction becomes high, resulting in an increase in the 


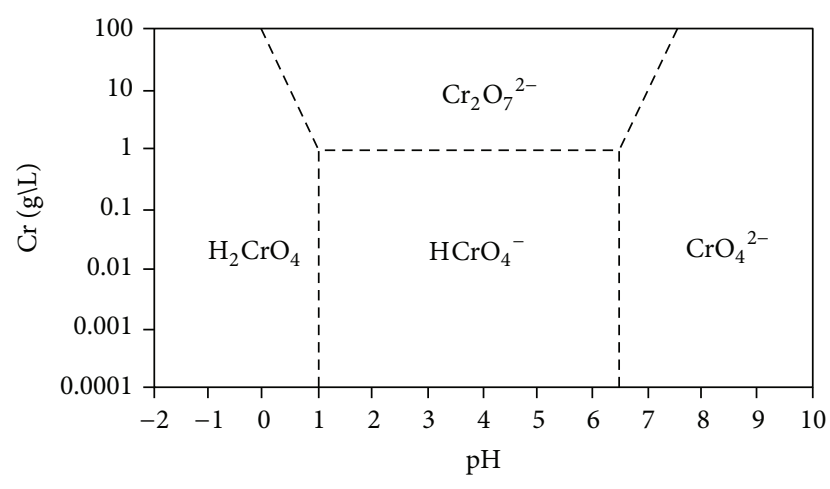

Figure 6: Speciation of Cr(VI).

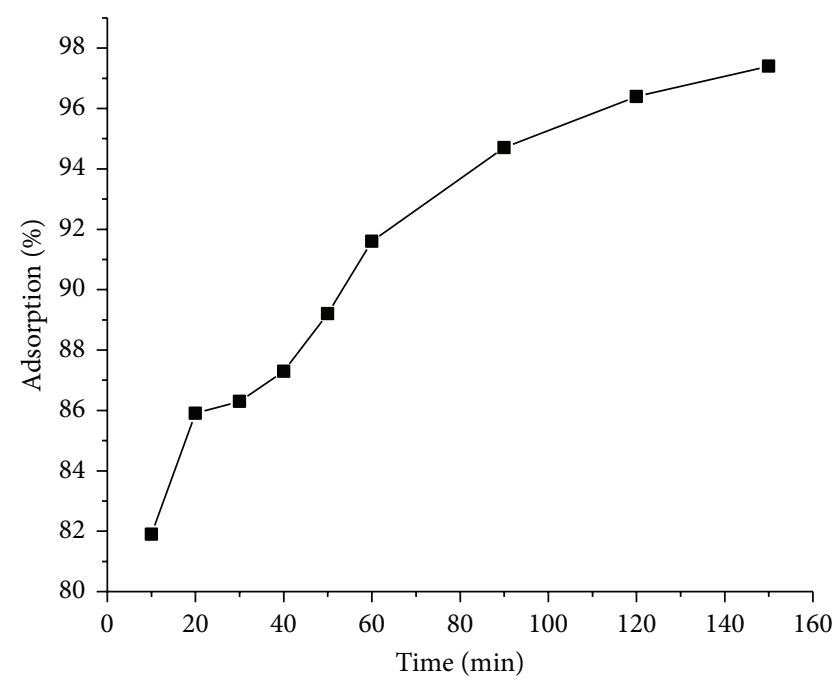

Figure 7: Effect of contact time on Cr(VI) adsorption.

attraction of anionic species of $\mathrm{Cr}(\mathrm{VI})$ towards adsorbent coffee resins. The decrease in adsorption above $\mathrm{pH} 4$ may be due to saturation of the adsorption sites by anionic species like $\mathrm{CrO}_{4}{ }^{2-}$ and $\mathrm{Cr}_{2} \mathrm{O}_{7}{ }^{2-}$ which retards the adsorption of such ions further towards the adsorbent surface. In other words, as the $\mathrm{pH}$ increased above the zeta potential of the adsorbent there is a reduction in the electrostatic attraction between the $\mathrm{Cr}(\mathrm{VI})$ species and the adsorbent surface.

3.4. Effect of Contact Time. Time of contact has a significant influence on the adsorption of $\mathrm{Cr}(\mathrm{VI})$. The adsorption experiments were carried out with respect to contact time ranging from 10 to $150 \mathrm{~min}$ and the results are presented in Figure 7. The results indicated that metal adsorption increases with contact time. For the first $10 \mathrm{~min}$, the percentage removal of $\mathrm{Cr}(\mathrm{VI})$ from aqueous solution increases rapidly and reaches a value of $81 \%$; later on adsorption rate becomes slower and reaches up to $97 \%$ at $150 \mathrm{~min}$. Further increase in contact time has a negligible effect on the percentage removal of $\mathrm{Cr}(\mathrm{VI})$. The fast initial uptake may be due to the accumulation of metal ions on the surface of adsorbent which is a rapid step.

The mechanism of solute transfer to the solid includes diffusion through the fluid film around the adsorbent particle
TABLE 3: Particle size analysis of coffee resins.

\begin{tabular}{lcccccc}
\hline Sr. no. & Resin code \\
\hline \multirow{2}{*}{1} & CFA & 01 & 02 & 03 & 04 & 05 \\
& Particle size $(\mu \mathrm{m})$ & - & 28.89 & 18.79 & 28.43 & 20.85 \\
\hline \multirow{2}{*}{2} & CAA & 01 & 02 & 03 & 04 & 05 \\
& Particle size $(\mu \mathrm{m})$ & 16.71 & 26.23 & 20.64 & 22.70 & 20.77 \\
\hline
\end{tabular}

and pores to the internal adsorption sites. Initially, the concentration gradient between the film and the solid surface is high, and hence the transfer of solute onto the solid surface is faster. Thus, it takes a smaller amount of time to attain $81 \%$ percent removal of $\mathrm{Cr}(\mathrm{VI})$. As the contact time increases, intraparticle diffusion becomes predominant. Hence, after $81 \%$ adsorption, solute takes more time in the transfer of $\mathrm{Cr}(\mathrm{VI})$ from solid surface to internal adsorption sites through the pores. Therefore, the optimum time for adsorption of $\mathrm{Cr}(\mathrm{VI})$ on coffee polyphenol-formaldehyde/acetaldehyde resins is $150 \mathrm{~min}$ for all batch studies.

3.5. SEM and EDX Analysis. The morphological analysis of coffee resins was performed by SEM as shown in Figure 8. Many small pores and particles $>5 \mu \mathrm{m}$ diameter are observed on the surface of coffee polyphenol-formaldehyde/acetaldehyde resins. EDX spectrum (Figure 9) also showed a peak at $5.4 \mathrm{keV}$, which confirmed that $\mathrm{Cr}(\mathrm{VI})$ was adsorbed on coffee polyphenol-formaldehyde/acetaldehyde resins. It supports that the reaction of metal ion and phenolic $-\mathrm{OH}$ group on coffee polyphenol-formaldehyde/acetaldehyde resins surface may be partly ion exchange or complexation. The results of analysis of particle size and particle size distribution are reported in Table 3. A plot of particle size distribution of coffee polyphenol-formaldehyde/acetaldehyde resins (CAA 05) is depicted in Figure 10. CFA resins showed higher particle sizes than CAA resins.

3.6. Effect of Chromium(VI) Concentration. Adsorption of $\mathrm{Cr}(\mathrm{VI})$ is significantly influenced by the concentration of $\mathrm{Cr}(\mathrm{VI})$ in aqueous solutions. The adsorption of $\mathrm{Cr}(\mathrm{VI})$ was examined with respect to the amount of $\mathrm{Cr}(\mathrm{VI})$ in solution. The $\mathrm{Cr}(\mathrm{VI})$ concentration varied from 5 to $20 \mathrm{ppm}$. The effect of initial concentration on percentage removal of $\mathrm{Cr}(\mathrm{VI})$ is depicted in Figure 11. The percentage removal of $\mathrm{Cr}(\mathrm{VI})$ decreases with the increase in initial $\mathrm{Cr}(\mathrm{VI})$ concentration. It may be due to an increase in the number of $\mathrm{Cr}(\mathrm{VI})$ ions for a fixed amount of adsorbent. The rate of percent $\mathrm{Cr}(\mathrm{VI})$ removal is higher at the beginning due to larger surface area of coffee resins being available for the adsorption. Once saturation point is reached the capacity of the adsorbent gets exhausted and uptake rate is controlled by the sorbate, transported from the exterior to the interior sites of the adsorbent particles. The results indicated that the initial $\mathrm{Cr}(\mathrm{VI})$ ion concentration determines the equilibrium concentration and also determines the rate of uptake of $\mathrm{Cr}(\mathrm{VI})$ ion and its kinetic character.

3.7. Effect of Adsorbent Dose. The various doses consisting of the adsorbents (100 $\mathrm{mg}$ to $300 \mathrm{mg}$ ) were mixed with metal 


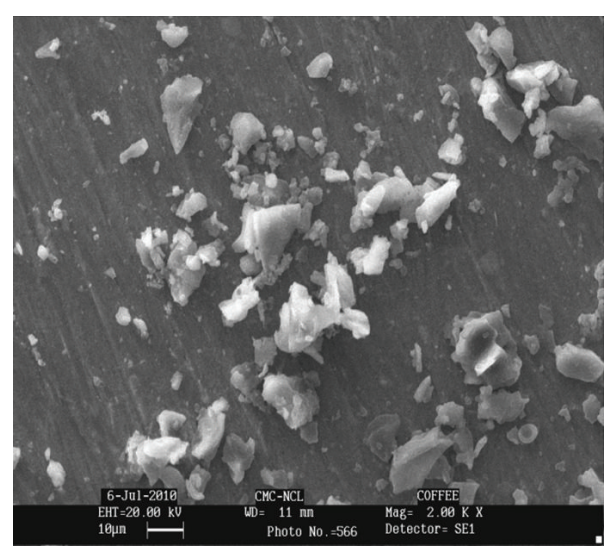

Coffee $2 \mathrm{KX}$

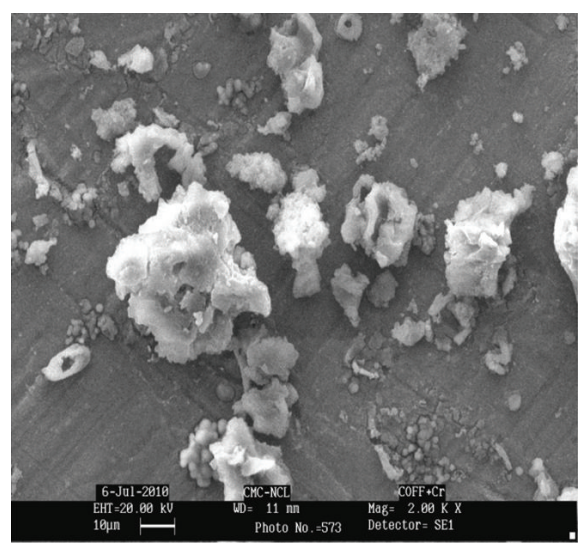

Coffee $\mathrm{Cr}(\mathrm{VI}) 2 \mathrm{KX}$

FIGURE 8: SEM photographs of coffee resins.
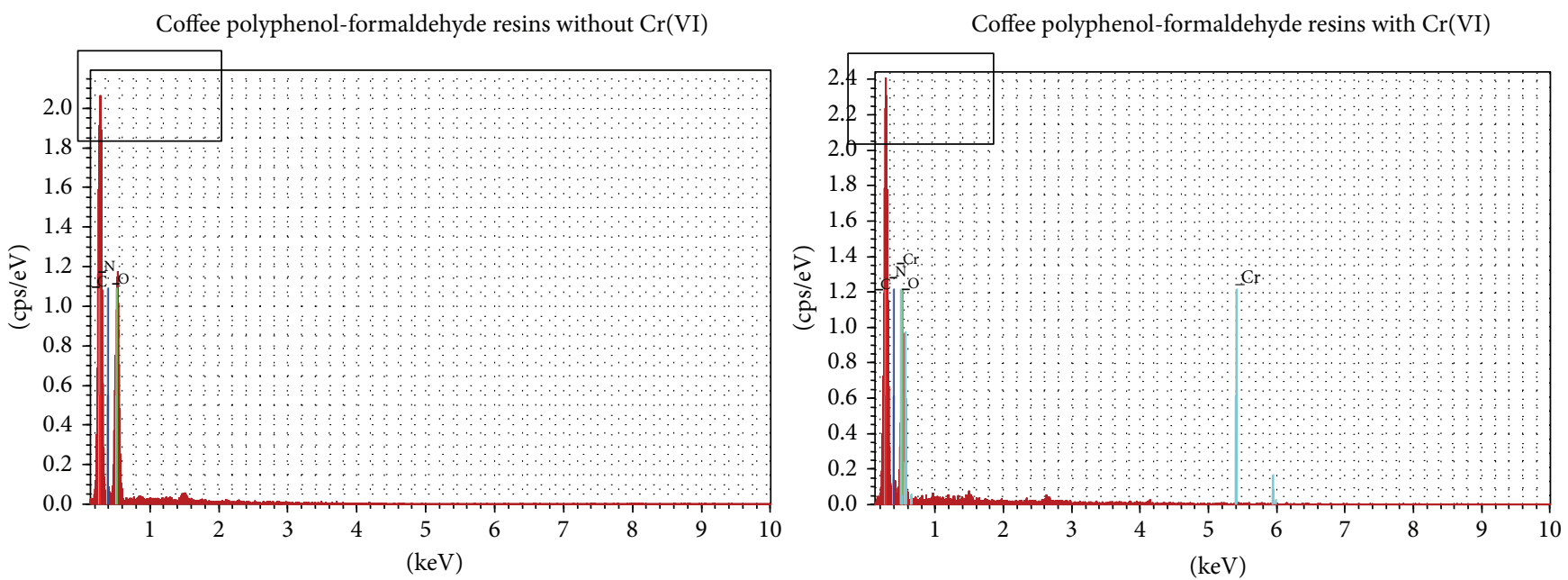

Figure 9: EDX spectra of coffee resins.

ion solutions and kept at room temperature for $24 \mathrm{~h}$. The adsorption capacities for different doses were determined by keeping all other factors constant, for example, $\mathrm{pH}$ and temperature. The effect of adsorbent dose on the adsorption of $\mathrm{Cr}(\mathrm{VI})$ is presented in Figure 12. It inferred that the percent removal of $\mathrm{Cr}(\mathrm{VI})$ increases with the increase in the weight of adsorbent dose (coffee resins). This may be due to the greater availability of the exchangeable sites or surface area at higher concentration of the adsorbent. If the adsorbent amount is increased by keeping the $\mathrm{Cr}(\mathrm{VI})$ concentration constant, then the amount of $\mathrm{Cr}(\mathrm{VI})$ adsorbed per unit mass decreased due to availability of lower number of $\mathrm{Cr}(\mathrm{VI})$ ions per unit mass of adsorbent. For $35.2 \mathrm{ppm}$ of $\mathrm{Cr}(\mathrm{VI})$ concentration at $\mathrm{pH}$ 2 , optimum values of percentage adsorption and adsorbent concentration are $99 \%$ and $200 \mathrm{mg}$, respectively.

3.8. Desorption Study. Desorption studies help to elucidate the nature of adsorption and recycling of the adsorbent. Adsorption of any solute on adsorbent takes place by physical bonding, ion-exchange, or a combination of both. If the adsorbed $\mathrm{Cr}(\mathrm{VI})$ is desorbed by water at neutral $\mathrm{pH}$, then the bonding of $\mathrm{Cr}(\mathrm{VI})$ with the adsorbent is physical. If hydrochloric acid or alkaline solution desorbed the $\mathrm{Cr}(\mathrm{VI})$, then the adsorption takes place by ion exchange. If organic acids, like acetic acid, desorbed the $\mathrm{Cr}(\mathrm{VI})$, then the $\mathrm{Cr}(\mathrm{VI})$ is held by chemisorption [26, 27]. Various eluents such as hydrochloric acid, nitric acid, and acetic acid are used. The effect of various eluents used for desorption studies indicates that hydrochloric acid is a better eluent for desorption, because results showed that the removal of adsorbed chromium ions was more than $75 \%$. The reversibility of adsorbed $\mathrm{Cr}(\mathrm{VI})$ in mineral acid or base is in agreement with the $\mathrm{pH}$ dependent results obtained $[28,29]$.

The reusability of the resin is important to reduce the process cost. Desorption was performed by using $1 \mathrm{M}$ hydrochloric acid. The metal desorbed resin was reused for three times and it shows good results. Figure 13 represents the adsorption-desorption cycle of CFA 01 resin. There was no significant change in adsorption capacity after three cycles. Adsorption capacity of resin after the third cycle was reduced by $8.68 \%$ compared to the first cycle. Also, it was observed that desorption capacities were 75,72 , and $62 \%$ for the first, 


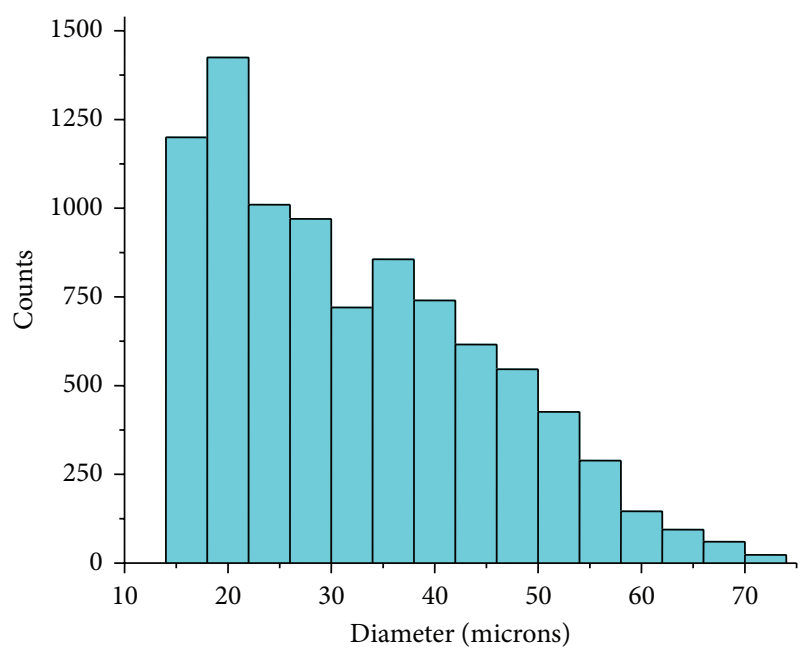

FIgURE 10: Particle size distribution of coffee resins.

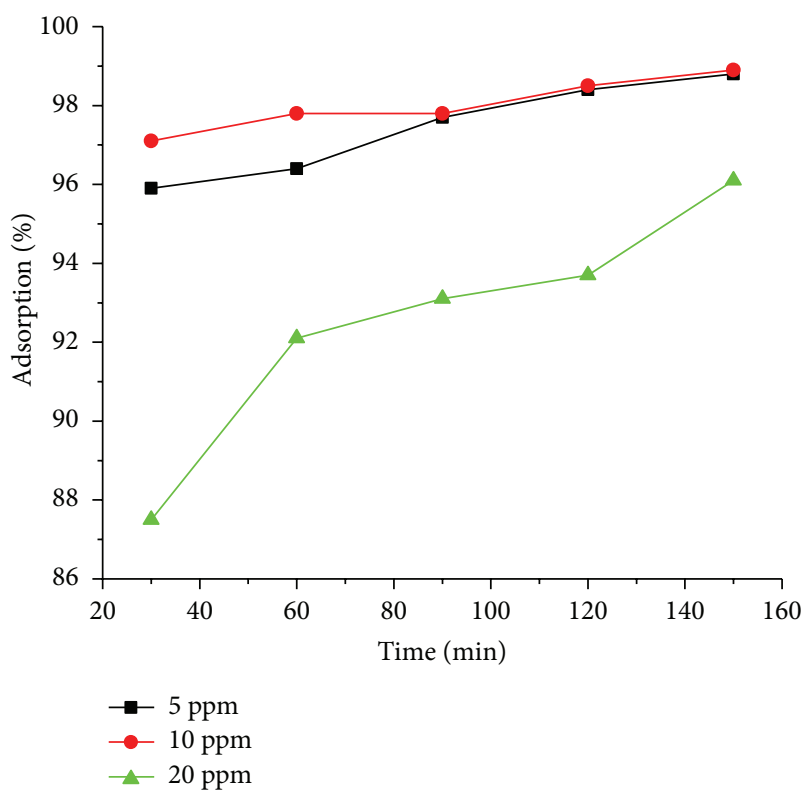

FIGURE 11: Effect of $\mathrm{Cr}(\mathrm{VI})$ concentration on adsorption.

second, and third cycle, respectively. These results show that coffee resins are effective and efficient adsorbent for $\mathrm{Cr}(\mathrm{VI})$ recovery.

3.9. Adsorption Isotherm. Adsorption isotherms of $\mathrm{Cr}(\mathrm{VI})$ were investigated with respect to biomaterials using an electrolyte solution at the optimum $\mathrm{pH}$ 2. The adsorption data were fitted by least square method to linearly transformed Freundlich and Langmuir adsorption isotherms.

The Freundlich adsorption isotherm was applied for the adsorption of $\mathrm{Cr}(\mathrm{VI})$ onto coffee polyphenol-formaldehyde resins. The linear Freundlich equation is mentioned below:

$$
\log q_{e}=\log K_{f}+\frac{1}{n} \log C_{e},
$$

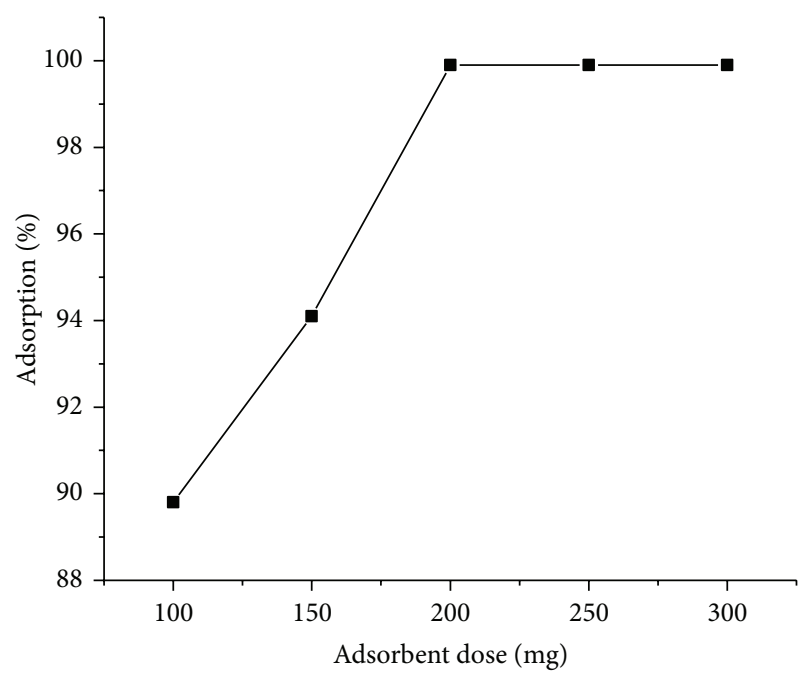

FIGURE 12: Effect of adsorbent dose on Cr(VI) adsorption.

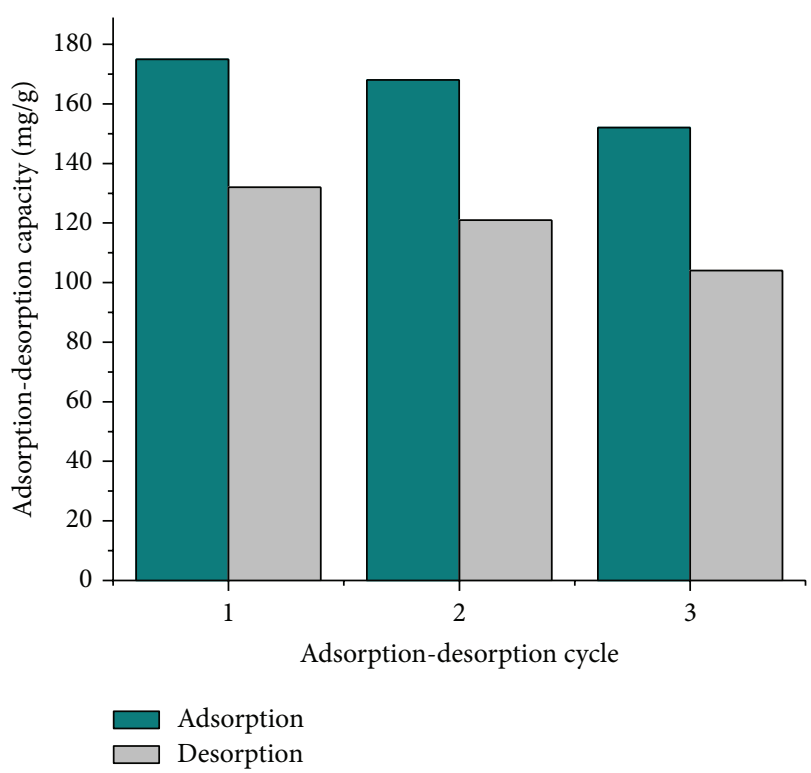

FIGURE 13: Adsorption-desorption cycle of CFA 01 resin.

where $q_{e}$ is the amount of $\mathrm{Cr}(\mathrm{VI})$ adsorbed per unit mass of adsorbent $(\mathrm{mg} / \mathrm{g}), C_{e}$ is the residual concentration of $\mathrm{Cr}(\mathrm{VI})$ in solution $(\mathrm{mg} / \mathrm{L}), K_{f}$ is a constant which is a measure of adsorption capacity, and $1 / n$ is a measure of adsorption intensity. The linear Freundlich adsorption isotherm is shown in Figure 14.

The Langmuir adsorption was applied to the present study to estimate the adsorption capacity of coffee polyphenol-formaldehyde resins. The linear form of the Langmuir adsorption isotherm is presented below:

$$
\frac{C_{e}}{q_{e}}=\frac{1}{Q_{0}{ }^{b}}+\frac{C_{e}}{Q_{0}},
$$

where $C_{e}$ is the equilibrium concentration $(\mathrm{mg} / \mathrm{L})$ and $q_{e}$ is the amount of $\mathrm{Cr}(\mathrm{VI})$ adsorbed per gram at equilibrium 


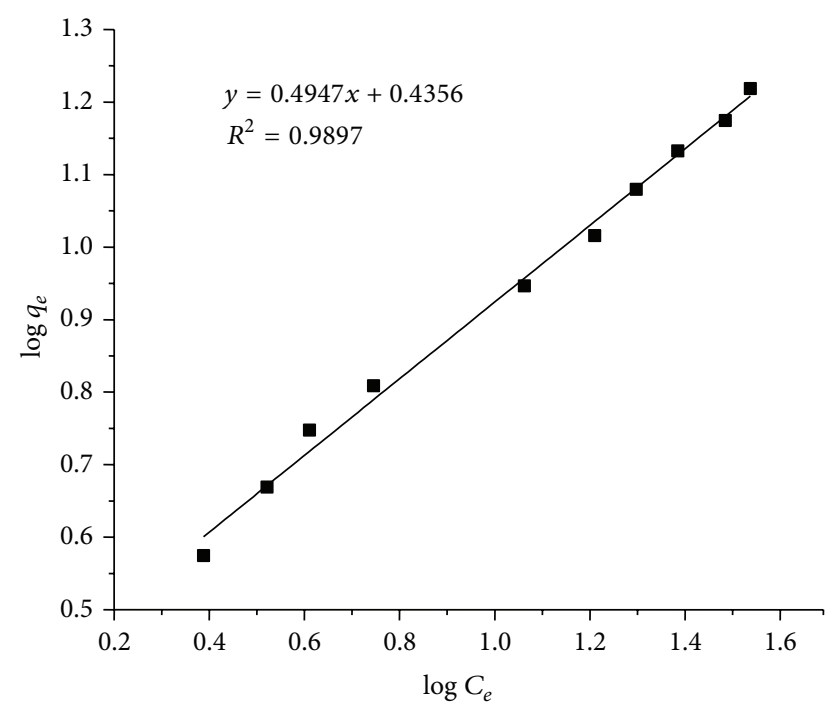

Figure 14: Freundlich isotherm for adsorption of $\mathrm{Cr}(\mathrm{VI})$.

TABLE 4

\begin{tabular}{lccc}
\hline$Q_{0} \mathrm{mg} / \mathrm{g}$ (calculated) & $\mathrm{Q}_{0} \mathrm{mg} / \mathrm{g}$ (found) & $b(\mathrm{~L} / \mathrm{mg})$ & $R^{2}$ \\
\hline 16.551 & 19.342 & 0.1007 & 0.9485 \\
\hline
\end{tabular}

TABLe 5

\begin{tabular}{lccc}
\hline$K_{f} \mathrm{mg} / \mathrm{g}$ (calculated) & $q_{e} \mathrm{mg} / \mathrm{g}$ (found) & $n$ & $R^{2}$ \\
\hline 0.3517 & 2.727 & 2.0214 & 0.9897
\end{tabular}

$(\mathrm{mg} / \mathrm{g}) . Q_{0}(\mathrm{mg} / \mathrm{L})$ and $b$ (adsorbent per mg of adsorbate) are Langmuir constants related to the adsorption capacity and energy of adsorption, respectively.

The results obtained from the adsorption experiments conducted at room temperature are fitted in Langmuir equation; linear plot was obtained for $C_{e} / q_{e}$ versus $C_{e}$ and is depicted in Figure 15. The high value of correlation coefficient $\left(R^{2}=0.948\right)$ indicates a good agreement with the parameters and confirms the monolayer adsorption of $\mathrm{Cr}(\mathrm{VI})$ onto the adsorbent surface. The isotherm data is linear using the Freundlich and Langmuir equations. The high value of correlation coefficient $\left(R^{2}=0.989\right)$ was found to be in good agreement with Freundlich equation.

These results indicated that adsorption of $\mathrm{Cr}(\mathrm{VI})$ followed both adsorption isotherm models. Freundlich isotherm model is fitted better than Langmuir, because the correlation between calculated and experimental (found) values as well as regression factors is in good agreement with Freundlich isotherm rather than Langmuir.

Langmuir constants were determined and are presented in Table 4.

Freundlich constants were determined and are depicted in Table 5.

To evaluate sorption dynamics, it requires consideration of two important physicochemical parameters such as kinetics and equilibrium of adsorption. Kinetics describe the solute uptake rate which governs the contact time.

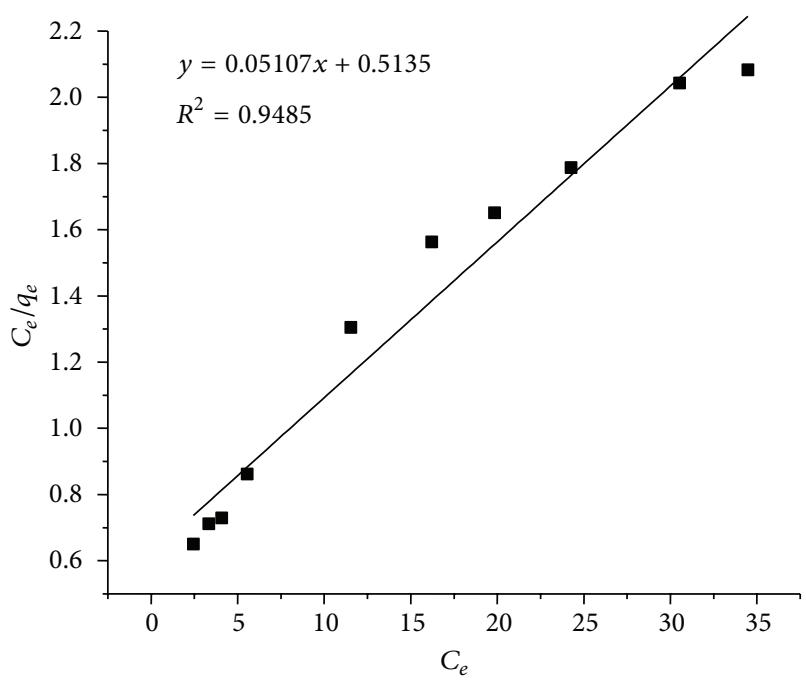

FIGURE 15: Langmuir isotherm for adsorption of Cr(VI).

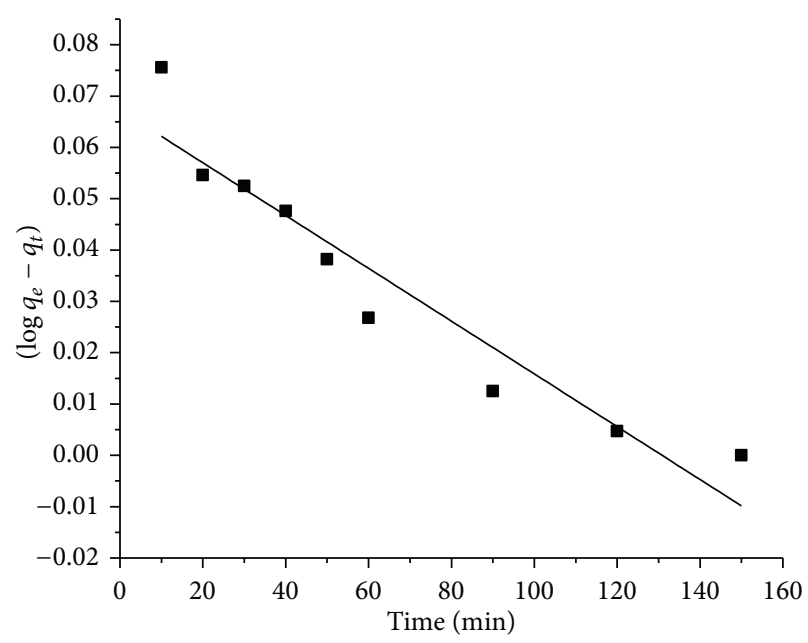

Figure 16: Pseudo-first order reaction.

The study of equilibrium is determining the distribution of solute between solid-liquid phases and determining the feasibility and capacity of the sorbent for adsorption. Several kinetic models, currently in use to explain the mechanism of adsorption progress, are most simple and widely used is pseudo-first order equation of Lagergren [30]:

$$
\log \left(q_{e}-q_{t}\right)=\log q_{e}-\frac{k_{a d} t}{2.303}
$$

where $q_{e}$ is the mass of metal adsorbed at equilibrium $(\mathrm{mg} / \mathrm{g})$, $q_{t}$ is mass of metal adsorbed at time $t(\mathrm{mg} / \mathrm{g})$, and $K_{a d}$ is the first order reaction constant $(\mathrm{L} / \mathrm{min})$. The pseudo-first order considers that the rate of occupation of adsorption sites is proportional to the number of unoccupied sites. A straight line of $\log \left(q_{e}-q_{t}\right)$ versus $t$ indicates the application of the first order kinetic model (Figure 16). 


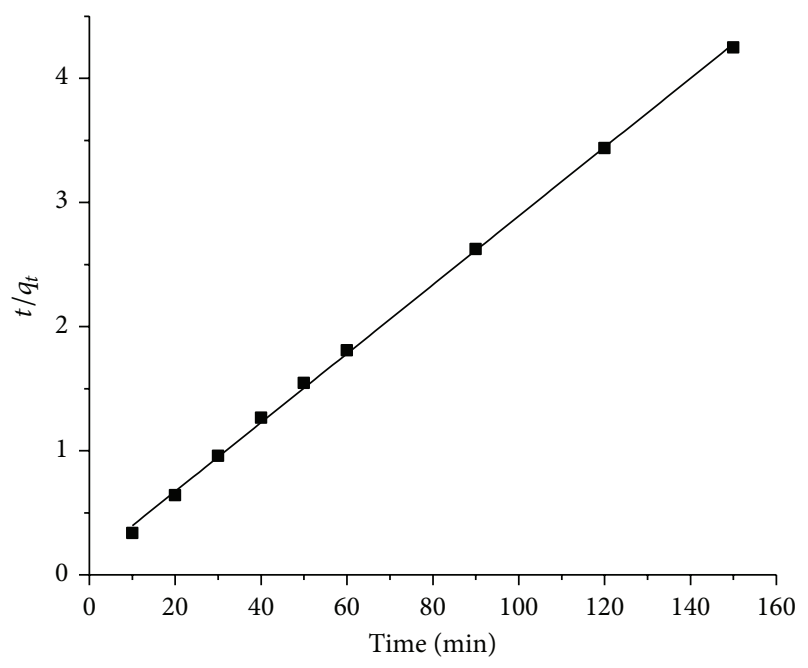

Figure 17: Pseudo-second order reaction.

TABLE 6: Comparison of adsorption of $\mathrm{Cr}(\mathrm{VI})$ with naturally occurring adsorbents.

\begin{tabular}{lccc}
\hline Sr. no. & Biosorbent & $\mathrm{Cr}(\mathrm{VI})(\mathrm{mg} / \mathrm{g})$ & Reference no. \\
\hline 1 & Rice husk carbon & 45.6 & {$[31]$} \\
2 & Iron(III) hydroxide & 0.47 & {$[32]$} \\
3 & Waste tea & 1.63 & {$[33]$} \\
4 & Irish sphagnum moss peat & 119 & {$[34]$} \\
5 & Saw dust & $10.1,16.05,4.44$ & {$[35-37]$} \\
6 & Blast furnace slag & 7.5 & {$[38]$} \\
7 & Activated red mud & 1.6 & {$[39]$} \\
8 & Waste tyre & 58.48 & {$[40]$} \\
9 & Olive cake & 33.44 & {$[41]$} \\
10 & Distillery sludge & 5.7 & {$[42]$} \\
11 & Coffee husk & 44.95 & {$[43]$} \\
12 & CFA and CAA resins & $175.44,143.32$ & This study \\
\hline
\end{tabular}

On the other hand, equilibrium capacity may be expressed by pseudo-second order equation as follows:

$$
\frac{t}{q_{t}}=\frac{1}{K_{2 a d} q_{e}^{2}}+\frac{t}{q_{e}}
$$

where $K_{2 a d}$ is the second order reaction rate equilibrium constant (g/mg.min). A plot of $t / q_{t}$ versus $t$ gives a linear relationship for the applicability of the second order kinetic model (Figure 17).

The adsorption capacity of coffee polyphenol resins compared to other materials is reported in the literature [31-43] and is given in Table 6. The sorption capacity of CFA and CAA resins are 175.44 and $143.32 \mathrm{mg} / \mathrm{g}$, respectively, which are higher than adsorbents reported in the literature such as industrial as well as low-cost natural materials. And the second advantage is that resins can be reused number of times by adsorption-desorption method due to better thermal and mechanical performance than without cross-linked natural materials, ultimately reducing the cost.
Most of the low-cost adsorbents have the limitations such as low adsorption capacity and also generate more solid waste causing disposal problems. Hence, there is a need to explore low-cost adsorbents with high adsorption capacity. In our study, we have prepared particulate systems where average particle size ranges are 20.85 to $28.89 \mu \mathrm{m}$ for CFA resins and 16.71 to $26.23 \mu \mathrm{m}$ for CAA resins.

\section{Conclusion}

The use of bioadsorbent prepared from coffee powder, capable of adsorption of $\mathrm{Cr}(\mathrm{VI})$ from aqueous stream, is cost effective and efficient. The maximum adsorption of $\mathrm{Cr}(\mathrm{VI})$ took place at $\mathrm{pH}$ 2. The active form of $\mathrm{Cr}(\mathrm{VI})$ adsorbed onto coffee polyphenol-formaldehyde/acetaldehyde resins at lower $\mathrm{pH}$ is found to be $\mathrm{HCrO}_{4}^{-}$. The percentage of the removal of $\mathrm{Cr}(\mathrm{VI})$ decreases with the increase in $\mathrm{pH}$. The adsorption process of $\mathrm{Cr}(\mathrm{VI})$ is described by Freundlich and Langmuir isotherm models. However, Freundlich isotherm model shows a better agreement with the equilibrium data. The kinetic studies indicate that $\mathrm{Cr}(\mathrm{VI})$ adsorption on coffee polyphenol-formaldehyde/acetaldehyde resins is very fast (within the first 150 minutes). Percentage removal of $\mathrm{Cr}(\mathrm{VI})$ increases and adsorption capacity decreases with the increase in adsorbent amount, because of the availability of more adsorption sites. These results demonstrate the great potential of coffee polyphenol-formaldehyde/acetaldehyde resins which provide a convenient and low-cost adsorbent for heavy metal removal. Heavy metal ion $\mathrm{Cr}(\mathrm{VI})$ removal technique using such biomaterials would be an effective method for economic treatment of wastewater.

\section{Acknowledgment}

The authors would like to thank the Department of Science and Technology, New Delhi, India, for their generous support in this research under the Program no. SR/S3/CE/0049/2010.

\section{References}

[1] S. Arivoli, M. Hema, M. Karuppaiah, and S. Saravanan, "Adsorption of chromium ion by acid activated low cost carbonkinetic, mechanistic, thermodynamic and equilibrium studies," E-Journal of ChEmistry, vol. 5, no. 4, pp. 820-831, 2008.

[2] K. Mohanty, M. Jha, B. C. Meikap, and M. N. Biswas, "Removal of chromium (VI) from dilute aqueous solutions by activated carbon developed from Terminalia arjuna nuts activated with zinc chloride," Chemical Engineering Science, vol. 60, no. 11, pp. 3049-3059, 2005.

[3] N. S. Rawat and D. Singh, "Removal of chromium in Bituminous coal," Asian Environment, vol. 14, pp. 30-34, 1992.

[4] American Water Works Association, Water Quality and Treatment: A Handbook of Community Water Suppliers, McGrawHill, New York, NY, USA, 1990.

[5] G. Cetin, S. Kocaoka, and G. Akcin, "Removal and recovery of chromium from solutions simulating tannery wastewater by strong acid cation exchange," Journal of Chemistry, vol. 2013, Article ID 158167, 7 pages, 2013. 
[6] V. Camel, "Solid phase extraction of trace elements," Spectrochimica Acta B, vol. 58, no. 7, pp. 1177-1233, 2003.

[7] A. M. Starvin and T. P. Rao, "Removal and recovery of mercury(II) from hazardous wastes using 1-(2-thiazolylazo)2-naphthol functionalized activated carbon as solid phase extractant," Journal of Hazardous Materials, vol. 113, no. 1-3, pp. 75-79, 2004.

[8] C. Shuyu, Z. Zhifeng, and Y. Huaming, "Dithione as chelator in the flow injection separation and pre-concentration system of trace metals in biological samples," Analytica Chimica Acta, vol. 451, no. 2, pp. 305-311, 2002.

[9] K. Fujinaga, M. Ishida, Y. Seike, and M. Okumura, "Concentration of some transition metal chelates by using poly $(\mathrm{N}$ isopropylacrylamide-co-4-vinylpyridine) as a solid adsorbent," Analytial Sciences, vol. 17, pp. i1097-il101, 2001.

[10] M. M. Shouman, N. A. Fathy, S. A. Khedr, and A. A. Attia, "Comparative biosorption studies of hexavalent chromium ion onto raw and modified branches," Advanced Physical Chemistry, vol. 2013, Article ID 159712, 9 pages, 2013.

[11] H. Sun, W. Kang, S. Liang, J. Ha, and S. Shen, "Determination of chromium (VI) and total chromium in water by derivative atomic absorption spectrometry using flow injection on-line pre-concentration with a double microcolumn," Analytical Sciences, vol. 19, no. 4, pp. 589-592, 2003.

[12] A. Babarinde, J. O. Babalola, J. Adigoke et al., "Biosorption of $\mathrm{Ni}(\mathrm{II}), \mathrm{Cr}(\mathrm{III})$, and $\mathrm{Co}(\mathrm{II})$ from solution using Acylapha hispida leaf: kinetics, equilibrium and thermodynamics," Journal of Chemistry, vol. 2013, Article ID 460635, 8 pages, 2013.

[13] M. J. Marques, A. Salvador, A. M. Rubio, and M. de la Guardia, "Chromium speciation in liquid matrices: a survey of the literature," Fresenius Journal of Analytical Chemistry, vol. 367, no. 7, pp. 601-613, 2000.

[14] S. Sugashini and K. M. M. S. Begum, "Column adsorption studies for the removal of $\mathrm{Cr}(\mathrm{IV})$ ions by ethylamine modified chitosan carbonised rice husk composite beads with modeling and optimization," Journal of Chemistry, vol. 2013, Article ID 460971, 11 pages, 2013.

[15] S. Kocaoba and G. Akcin, "Removal and recovery of chromium and chromium speciation with MINTEQA2," Talanta, vol. 57, no. 1, pp. 23-30, 2002.

[16] Y. M. Scindia, A. K. Pandey, A. V. R. Reddy, and S. B. Manohar, "Selective preconcentration and determination of chromium(VI) using a flat sheet polymer inclusion sorbent: potential application for $\mathrm{Cr}(\mathrm{VI})$ determination in real samples," Analytical Chemistry, vol. 74, no. 16, pp. 4204-4212, 2002.

[17] E. Vassileva, K. Hadjiivanov, T. Stoychev, and C. Daiev, "Chromium speciation analysis by solid-phase extraction on a high surface area $\mathrm{TiO}_{2}$," Analyst, vol. 125, no. 4, pp. 693-698, 2000.

[18] P. G. Krishna, J. M. Gladis, U. Rambabu, T. P. Rao, and G. R. K. Naidu, "Preconcentrative separation of chromium(VI) species from chromium(III) by coprecipitation of its ethyl xanthate complex onto naphthalene," Talanta, vol. 63, no. 3, pp. 541-546, 2004.

[19] J. Chwastowska, W. Skwara, E. Sterlińska, and L. Pszonicki, "Speciation of chromium in mineral waters and salinas by solid-phase extraction and graphite furnace atomic absorption spectrometry," Talanta, vol. 66, no. 5, pp. 1345-1349, 2005.

[20] G. A. Spiller, "Caffeine," in The Chemical Components of Coffee, M. A. Spiller, Ed., chapter 6, CRC Press, New York, NY, USA, 1997.
[21] H. S. Lee and B. Volesky, "Interaction of light metals and protons with seaweed biosorbent," Water Research, vol. 31, no. 12, pp. 3082-3088, 1997.

[22] R. Tressl, D. Bahri, H. Köppler, and A. Jensen, "Diphenols and caramel compounds in roasted coffees of different varieties. II," Journal of Food Investigation and Research, vol. 167, no. 2, pp. 111-114, 1978.

[23] W. Rahn, H. W. Meyer, and W. A. Koenig, "Effects of the steam treatment on the composition of the phenolic compounds in green and roasted coffee," Journal of Food Investigation and Research, vol. 169, pp. 346-349, 1979.

[24] M. Windholz, The Merck Index, vol. 802, Merck \& Company, Whitehouse Station, NJ, USA, 9th edition, 1976.

[25] M. Sánchez-Polo and J. Rivera-Utrilla, "Adsorbent-adsorbate interactions in the adsorption of $\mathrm{Cd}(\mathrm{II})$ and $\mathrm{Hg}(\mathrm{II})$ on ozonized activated carbons," Environmental Science and Technology, vol. 36, no. 17, pp. 3850-3854, 2002.

[26] C. Namasivayam and K. Ranganathan, "Waste Fe(III)/Cr(III) hydroxide as adsorbent for the removal of $\mathrm{Cr}(\mathrm{VI})$ from aqueous solution and chromium plating industry wastewater," Environmental Pollution, vol. 82, no. 3, pp. 255-261, 1993.

[27] S. Arivoli, B. R. Venkatraman, T. Rajachandrasekar, and M. Hema, "Adsorption of ferrous ion from aqueous solution by acid activated low cost carbon obtained from natural plant material," Research Journal of Chemistry and Environment, vol. 11, no. 1, pp. 70-78, 2007.

[28] S. Lahiri and K. Roy, "Investigation on $\mathrm{pH}$ dependent uptake of $\mathrm{Cr}(\mathrm{III})$ and $\mathrm{Cr}(\mathrm{VI})$ by baker's yeast," Indian Journal of Chemical Technology, vol. 15, no. 4, pp. 417-419, 2008.

[29] R. Prabakaran, S. Arivoli, M. Hema, and C. Kamatchi, "Removal of copper ion from aqueous solutions by low cost activated carbon from Thespesia populnea bark," Journal of Chemical and Pharmaceutical Research, vol. 3, no. 5, pp. 532-543, 2011.

[30] S. Lagergren, "Zur theorie der sorgenannten adsorption geloster sioffe, kungliga svenska ventenskapsakademiens," Handlingar, vol. 24, pp. 1-39, 1898.

[31] K. Srinivasan, N. Balasubramanian, and T. V. Ramakrishna, "Studies on chromium removal by rice husk carbon," Indian Journal of Environmental Health, vol. 30, no. 4, pp. 376-387, 1988.

[32] X. Hu, J. Wang, Y. Liu et al., "Adsoprtion of chromium(VI) by ethylenediamine-modified cross-linked magnetic chitosan resin: isotherm, kinetics and thermodynamics," Journal of Hazardous Materials, vol. 185, no. 1, pp. 306-314, 2011.

[33] Y. Orhan and H. Büyükgüngor, "The removal of heavy metals by using agricultural wastes," Water Science Technology, vol. 28, no. 2, pp. 247-255, 1993.

[34] D. C. Sharma and C. F. Forster, "Removal of hexavalent chromium using sphagnum moss peat," Water Research, vol. 27, no. 7, pp. 1201-1208, 1993.

[35] P. S. Bryant, J. N. Petersen, J. M. Lee, and T. M. Brouns, "Sorption of heavy metals by untreated red sawdust," Applied Biochemistry and Biotechnology, vol. 34-35, no. 1, pp. 777-788, 1992.

[36] V. P. Dikshit, "Removal of chromium (VI) by adsorption using sawdust," National Academy of Science Letters, vol. 12, pp. 419421, 1989.

[37] M. A. Zarraa, "Study on the removal of chromium(VI) from waste solutions by adsorption on to sawdust in stirred vessels," Adsorption Science and Technology, vol. 12, no. 2, pp. 129-138, 1995. 
[38] S. K. Srivastava, V. K. Gupta, and D. Mohan, "Removal of lead and chromium by activated slag-a blast-furnace waste," Journal of Environmental Engineering, vol. 123, no. 5, pp. 461$468,1997$.

[39] J. Pradhan, S. N. Das, and R. S. Thakur, "Adsorption of hexavalent chromium from aqueous solution by using activated red mud," Journal of Colloid and Interface Science, vol. 217, no. 1, pp. 137-141, 1999.

[40] N. K. Hamadi, X. D. Chen, M. M. Farid, and M. G. Q. Lu, "Adsorption kinetics for the removal of chromium(VI) from aqueous solution by adsorbents derived from used tyres and sawdust," Chemical Engineering Journal, vol. 84, no. 2, pp. 95105, 2001.

[41] M. Dakiky, M. Khamis, A. Manassra, and M. Mer'eb, "Selective adsorption of chromium(VI) in industrial wastewater using low-cost abundantly available adsorbents," Advances in Environmental Research, vol. 6, no. 4, pp. 533-540, 2002.

[42] K. Selvaraj, S. Manonmani, and S. Pattabhi, "Removal of hexavalent chromium using distillery sludge," Bioresource Technology, vol. 89, no. 2, pp. 207-211, 2003.

[43] N. Ahalya, R. D. Kanamadi, and T. V. Ramachandra, "Removal of hexavalent chromium using coffee husk," International Journal of Environment and Pollution, vol. 43, no. 1-3, pp. 106-116, 2010 . 

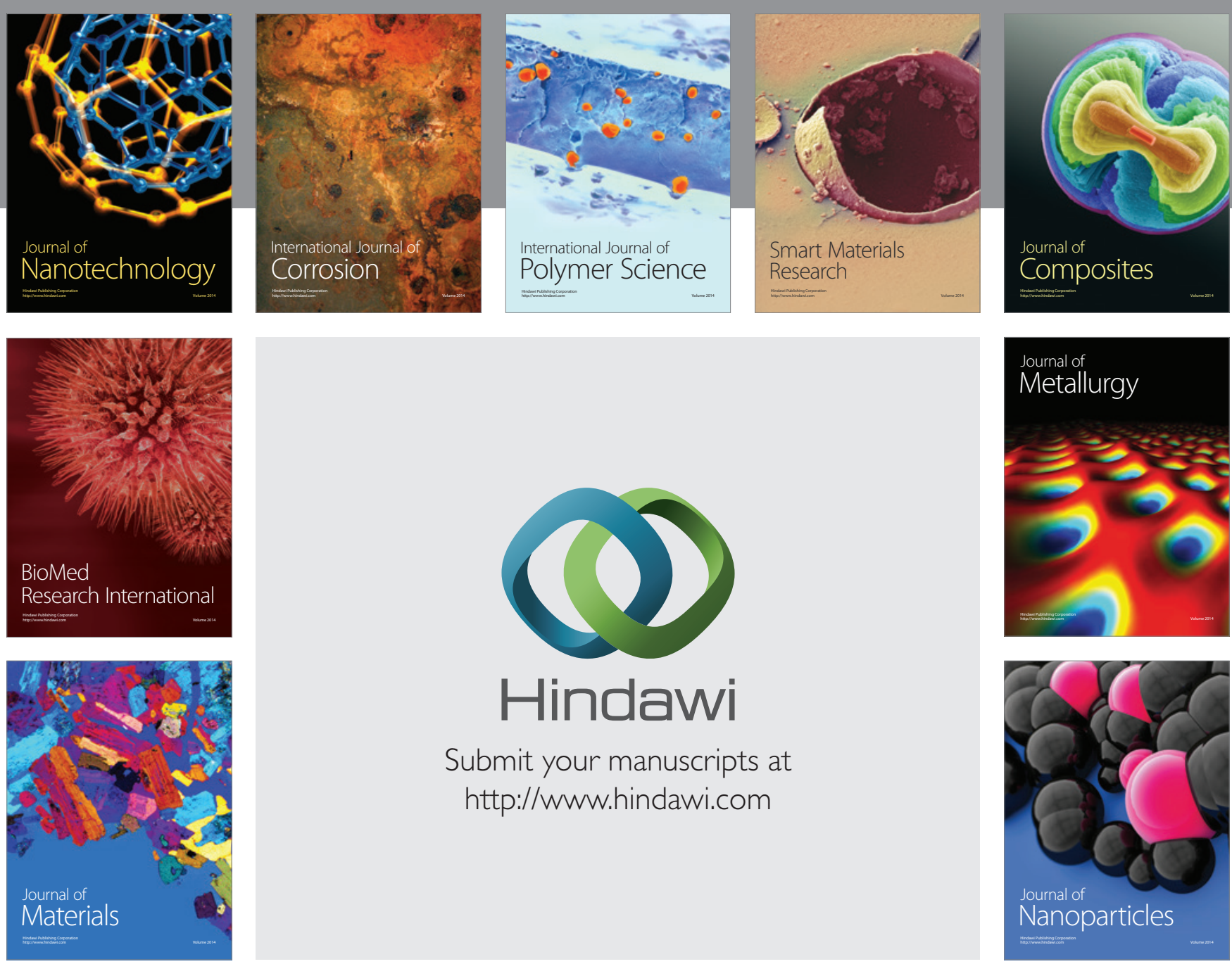

Submit your manuscripts at http://www.hindawi.com
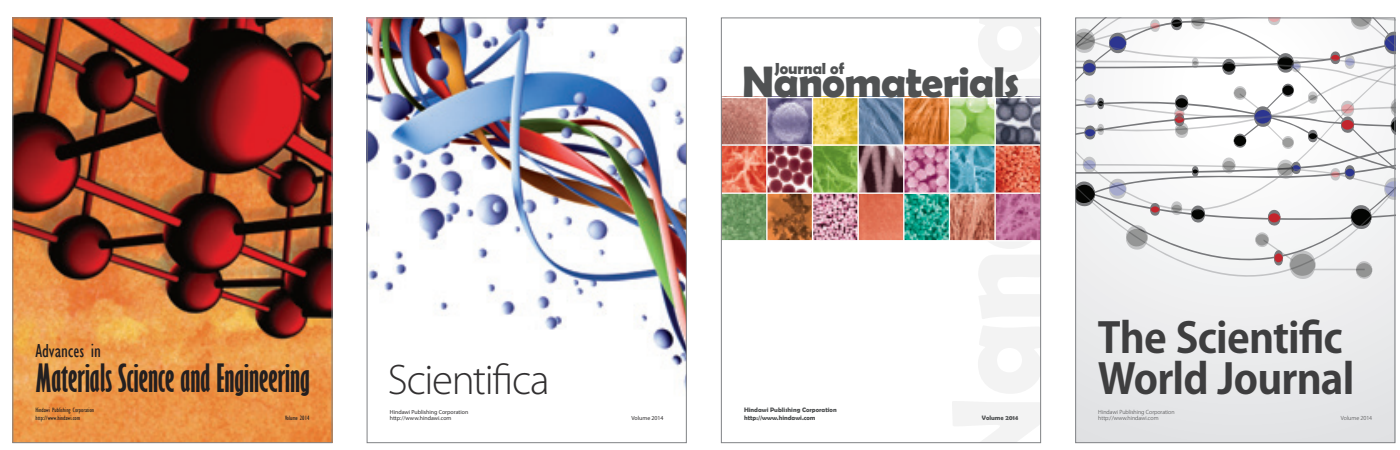

\section{The Scientific World Journal}
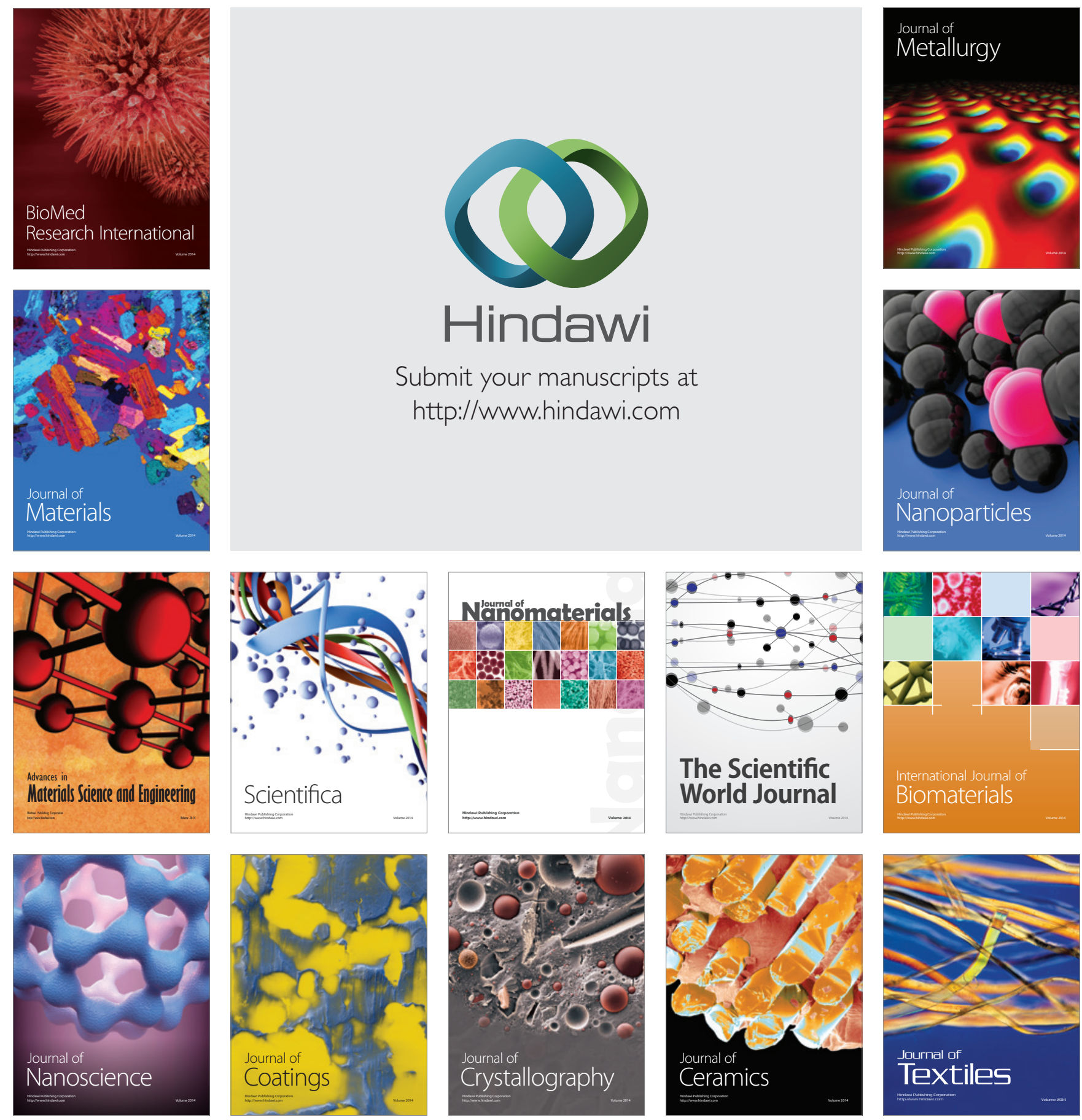